\title{
EFEITO DE DIFERENTES MÉTODOS DE EXTRAÇÃO SOBRE O TEOR DE COMPOSTOS FENÓLICOS DAS FOLHAS DE Ananas comosus var. erectifolius
}

\author{
$\underline{\text { Diego Mota da Costa }}{ }^{1}$; Hugo Neves Brandão ${ }^{2}$; Juliana Azevedo da Paixão ${ }^{3}$ Juceni $^{-}$ \\ Pereira de Lima David ${ }^{4}$; Danielle Figuerêdo da Silva ${ }^{5}$; Fernanda Vidigal Duarte de \\ Souza $^{6}$; Everton Hilo de Souza ${ }^{7}$ \\ 1. Bolsista PIBIC/CNPq, Graduando em Ciências Farmacêuticas, Universidade Estadual de Feira de Santana, e-mail: \\ diegocost@live.com \\ 2. Orientador, Departamento de Saúde, Universidade Estadual de Feira de Santana, e-mail: hugo@uefs.br \\ 3. Doutoranda em Química, Universidade Federal da Bahia, e-mail: juli.azevedo87@gmail.com \\ 4. Departamento do Medicamento, Universidade Estadual de Feira de Santana, e-mail: juceni@ufba.br \\ 5. Doutoranda em Recursos Genéticos e Vegetais, Universidade Estadual de Feira de Santana, e-mail: \\ danyfigs@hotmail.com \\ 6.EMBRAPA Mandioca e Fruticultura, Cruz das Almas, Brasil. fernanda.souza@embrapa.br \\ 7.Centro de Energia Nuclear da Agricultura, Cruz das Almas, Brasil. hilosouza@ gmail.com
}

PALAVRAS-CHAVE: Bromeliaceae; Fenóis; Extração.

\section{INTRODUÇÃO}

A família Bromeliaceae é de grande predominância no Brasil e apresenta cerca de $40 \%$ do total de espécies, sendo 40 gêneros registrados no território nacional. A espécie mais comum é o Ananas comosus (L.) Merr., conhecido como abacaxi, uma das frutas tropicais mais consumidas mundialmente. Comumente, algumas das plantas desta família são utilizadas para tratamento de diversas afecções, como: bronquites, aftas, tosses e inflamações em geral. Além de existir relatos da presença de bromelina, proteases de cisteína, metabólitos secundários como: triterpenos, esteroides, flavonoides, gliceróis, derivados do ácido cinâmico, entre outros (MANETTI, 2009).

Dentre alguns constituintes, se encontram os compostos fenólicos, que são amplamente distribuídos nas plantas e incluem diversas subclasses cuja principal atividade farmacológica estudada é a propriedade antioxidante. Dessa forma, os mesmos podem proteger os tecidos dos radicais livres formados naturalmente no próprio metabolismo, já que os fenólicos têm a capacidade de sequestrar esses radicais. Portanto, de forma a aprofundar o conhecimento sobre essas substâncias, as pesquisas em torno de espécies que as contenham se tornam muito importantes no desenvolvimento de novos produtos. Devido à grande importância dos compostos fenólicos, vêm se buscando a melhor forma de extração, no qual se obtenha a maior e mais variada quantidade desses compostos.

Dessa forma, o trabalho teve como objetivo comparar a constituição química da Ananas comosus var. erectifolius por diferentes formas de extração, através de técnica espectofotométrica.

\section{MATERIAL E MÉTODOS OU METODOLOGIA (ou equivalente)}

$\mathrm{O}$ material coletado foi submetido à secagem em estufa a $(45 \pm 3){ }^{\circ} \mathrm{C}$, durante 5 dias, ou até peso constante. Após a secagem, esse material foi moído em liquidificador industrial. Foram utilizadas três formas de extração: maceração, extração por ultrassom e refluxo. A maceração foi realizada utilizando metanol como solvente extrator. $\mathrm{O}$ solvente foi renovado a cada 5 dias, repetindo essa operação 5 vezes. A extração por 
ultrassom foi realizada através da melhor condição de extração descrita na literatura (50g de amostras, $400 \mathrm{~mL}$ de solvente durante 180 minutos de extração a $75^{\circ} \mathrm{C}$ ). A extração sob refluxo foi realizada pelo método adaptado de Falkenberg e col. (2004), que consiste em submeter o material vegetal à extração com um solvente em ebulição em aparelho acoplado a um condensador, de forma que o solvente evaporado durante o processo seja recuperado e retorne ao conjunto. Os extratos obtidos foram concentrados em evaporador rotativo sob pressão reduzida, com banho em temperatura de $(45 \pm 3){ }^{\circ} \mathrm{C}$ e posteriormente submetidos à partição líquido-líquido utilizando-se solventes de diferentes polaridades (hexano, clorofórmio e acetato de etila) para obtenção dos extratos hexânico, clorofórmico e acetato de etila.

A quantificação de fenólicos totais foi realizada através do método espectrofotométrico descrito primeiramente por Folin e Ciocalteu, adaptado da metodologia descrita por Oliveira (2009). Para a realização dos testes, preparou-se uma solução do reagente FC com diluição de 1:10 em água destilada e a solução de carbonato de sódio a 7,5\% em água destilada. Para a construção da curva de calibração, empregada na quantificação, foi utilizado o padrão ácido gálico, sendo preparadas soluções com água destilada. $\mathrm{O}$ preparo das amostras foi realizado utilizando $10 \mathrm{mg}$ dos extratos, diluídos em solução de $10 \mathrm{~mL}$ de metanol, em triplicata. Em tubos de ensaio, foram colocados $0,5 \mathrm{~mL}$ das diferentes concentrações de ácido gálico e das amostras em triplicata e adicionar 2,5 mL da solução-reagente de FC. Os tubos foram agitados para proporcionar a mistura do reagente com as amostras e deixados em repouso por 3 minutos. Após esse tempo, foram adicionados $2 \mathrm{~mL}$ da solução de carbonato de sódio a 7,5\% e os tubos foram colocados em aquecimento, em banho-maria, a $50^{\circ} \mathrm{C}$ por 5 minutos. Ao final do aquecimento, os tubos foram mantidos à temperatura ambiente por 15 minutos até o seu esfriamento e os mesmos foram colocados em banho de gelo para realização do choque térmico por mais 3 minutos. $\mathrm{O}$ controle negativo foi realizado da mesma forma que as demais amostras, contendo apenas o solvente no lugar dos extratos. Por fim, acrescentou-se $250 \mu \mathrm{L}$ da solução de cada tubo em uma placa de 96 poços e as leituras das absorbâncias foram realizadas em leitor de microplacas MultiskanTM GO 3.2, no comprimento de onda de $760 \mathrm{~nm}$.

\section{RESULTADOS E DISCUSSÃO}

O teor de fenólicos totais dos extratos obtidos variou entre 1,03 g EAG.100g-1 e 16,59 g EAG. $100 \mathrm{~g}^{-1}$ de extrato para os extratos clorofórmico obtido por ultrassom e acetato de etila obtido por refluxo, respectivamente. Os resultados podem ser observados na Tabela 1. Esses resultados foram obtidos com base na equação obtida através da curva de calibração de ácido gálico $(\mathrm{y}=4,9425 \mathrm{x}+0,1451)$ e $\mathrm{R}^{2}=0,9928$.

Tabela 1 - Média dos teores de fenólicos totais em g de AGE/100 g de extrato para os extratos de Ananas comosus var. erectifolius, acompanhado do desvio padrão

\begin{tabular}{ccc}
\hline Extrato & Método de extração & Medias \pm DP \\
\hline Mac A & $16,33 \pm 0,195481^{\mathrm{a}}$ \\
\cline { 2 - 3 } & Mac B & $16,39 \pm 0,213362^{\mathrm{a}}$ \\
\hline Mac C & $15,44 \pm 0,334704^{\mathrm{b}}$ \\
\hline
\end{tabular}




\begin{tabular}{|c|c|c|}
\hline \multirow{6}{*}{ Acet } & Ref A & $16,40 \pm 0,090597^{\mathrm{a}}$ \\
\hline & Ref B & $16,11 \pm 0,426198^{\mathrm{ab}}$ \\
\hline & Ref C & $16,59 \pm 0,301139^{a}$ \\
\hline & Ult A & $11,18 \pm 0,287166^{c}$ \\
\hline & Ult B & $13,19 \pm 0,387833^{\mathrm{d}}$ \\
\hline & Ult C & $12,59 \pm 0,479157^{\mathrm{e}}$ \\
\hline \multirow{9}{*}{ Clor } & Mac A & $5,50 \pm 0,322721^{\mathrm{e}}$ \\
\hline & Mac B & $5,00 \pm 0,128045^{\mathrm{ef}}$ \\
\hline & Mac C & $5,48 \pm 0,064716^{\mathrm{e}}$ \\
\hline & Ref A & $4,89 \pm 0,165385^{\mathrm{ef}}$ \\
\hline & Ref B & $4,50 \pm 0,154455^{f}$ \\
\hline & Ref C & $3,58 \pm 0,154455^{\mathrm{g}}$ \\
\hline & Ult A & $1,03 \pm 0,144347^{\mathrm{h}}$ \\
\hline & Ult B & $1,30 \pm 0,069192^{\mathrm{h}}$ \\
\hline & Ult C & $3,65 \pm 0,19359^{g}$ \\
\hline \multirow{9}{*}{ Hex } & Mac A & \multirow{3}{*}{ - } \\
\hline & Mac B & \\
\hline & Mac C & \\
\hline & Ref A & \multirow{3}{*}{ - } \\
\hline & Ref B & \\
\hline & Ref C & \\
\hline & Ult A & \multirow{3}{*}{-} \\
\hline & Ult B & \\
\hline & Ult C & \\
\hline
\end{tabular}

Hex: Extrato hexânico; Clor: Extrato clorofórmico; Acet: Extrato acetato de etila; (-): não detectado na amostra. Médias seguidas pela mesma letra minúscula, não diferem pelo teste de Tukey $(p<0,05)$.

Em trabalho realizado por Rodrigues (2018) as quantidades encontradas foram maiores no extrato acetato de etila e menores no hexânico, sendo os valores semelhantes, especialmente do extrato diclorometano (5,22 gAGE/100g de extrato) e extrato hexânico (2,22 gAGE/100g de extrato). Em estudo realizado por Silva (2013) foi observado que a fração acetato de etila de Bromelia sp. (284) apresentou total de fenólicos de 12,81 g de AGE /100g de extrato; a fração $\mathrm{CHCl}_{3}$ de Bromelia sp. (284), $10,61 \mathrm{~g}$ de AGE/100g de extrato; a fração acetato de Ananas macrodontes (081), 18,47g de AGE /100g de extrato; e fração AcOEt de Bromelia balansae (280), 18,97g de AGE $/ 100 \mathrm{~g}$ de extrato.

Os estudos citados acima corroboram com os resultados encontrados no presente trabalho, sendo os maiores teores de compostos fenólicos encontrados no extrato acetato de etila, seguido pelo extrato clorofórmico. Além disso não foi detectado a presença de fenóis no extrato hexânico, corroborando assim, com o trabalho realizado por Cechinel Filho e Yunes (1998) que identificaram a maior concentração de compostos fenólicos no extrato acetato, já que os fenóis são mais solúveis em extrato utilizando como solvente acetato de etila. 
As melhores técnicas para a extração de compostos fenólicos foram a maceração e refluxo, pois não apresentaram diferenças estatística. Entretanto, dentre elas, a melhor é a técnica por refluxo, pois utiliza-se menos solvente e se gasta menor tempo para realizar a extração.

\section{CONSIDERAÇÕES FINAIS}

De acordo com o presente trabalho, foi possível avaliar que a técnica refluxo foi a melhor para a extração de compostos fenólicos, uma vez que se utiliza uma menor quantidade de solvente e menor tempo para extração, através da quantificação de fenólicos totais por espectrofotometria. Além disso, o estudo se mostrou inovador para a amostra analisada, já que não foi encontrado na bibliografia pesquisada trabalhos acerca da determinação qualitativa e quantitativa, bem como comparando diferentes formas de extração. Portanto, os dados obtidos contribuem com a quimiossistemática do gênero estudado, além de servir como suporte para o desenvolvimento de novos trabalhos na área, que possam aprofundar e complementar os resultados encontrados.

\section{REFERÊNCIAS}

CECHINEL FILHO, V.; YUNES, R. A. 2004. Estratégias para a obtenção de compostos farmacologicamente ativos a partir de plantas medicinais: conceitos sobre modificação estrutural para otimização da atividade. Química Nova, p. 99-105, 1998. FALKENBERG, M. B.; SANTOS, R. I.; SIMÕES, C. M. O. 2004 Introdução à análise fitoquímica. In: Farmacognosia: da planta ao medicamento, UFRGS Editora, 5. ed., 1102p., cap. 10, p. 232-234

MANETTI, L. M.; DELAPORTE, R. H.; LAVERDE JUNIOR, A. 2009. Metabólitos secundários da família Bromeliaceae. Química Nova, v. 32, p. 1885-1897.

OLIVEIRA, A. C. et al. 2009. Fontes vegetais naturais de antioxidantes. Química Nova, v. 32, p. 689-702.

RODRIGUES, C. I. 2018. Caracterização química e avaliação de atividades biológicas in vitro da Cultivar BRS Boyrá (Ananas comosus). Universidade Estadual de Feira de Santana, Feira de Santana, MSc Diss.

SILVA, D.F. 2013. Avaliação da atividade antioxidante e da composição química das folhas de espécies de Bromeliaceae. 2013. Universidade Estadual de Feira de Santana, Feira de Santana, Monografia. 